\title{
Rheumatoid Nodules Predating Seroconversion and Rheumatoid Arthritis: An Uncommon Case Report
}

Roberta Gualtierotti ${ }^{1,2 *}$ and Francesca Ingegnoli,

${ }^{1}$ Division of Rheumatology, Istituto Gaetano Pini, Milan, Italy

${ }^{2}$ Department of Clinical Sciences and Community Health, University of Milan, Milan, Italy

\begin{abstract}
Rheumatoid nodulosis is a benign condition associated with mild or no arthritis. Differently from classical rheumatoid nodules, which are relatively common in patients with long-standing rheumatoid arthritis, particularly in rheumatoid factor (RF)-positive patients, rheumatoid nodulosis may rarely precede arthritis onset and even seroconversion. We describe the clinical course of a patient with isolated painful rheumatoid nodules, who subsequently experienced RF and anti-citrullinated protein antibodies (ACPA) seroconversion and finally developed overt rheumatoid arthritis. This case should raise clinical awareness to consider rheumatoid nodulosis as a possible diagnosis even in the absence of arthritis and of RF positivity, whenever facing with isolated subcutaneous nodules.
\end{abstract}

Keywords: Rheumatoid nodules; Benign; Rheumatoid nodulosis; Rheumatoid arthritis; Seroconversion; Rheumatoid factor; Anticitrullinated protein antibodies

\section{Introduction}

Rheumatoid nodulosis is a benign clinical entity associated with mild or no arthritis. Its diagnosis is straightforward when its typical histological features are found in patients with established rheumatoid arthritis (RA) but, if the rheumatoid nodules predate the onset of RA, a thorough differential diagnosis must be made based on clinical, laboratory and histological findings, and sometimes only follow-up will unravel the final diagnosis.

We report an uncommon case of a woman who initially came to our observation with isolated painful rheumatoid nodules, subsequently experienced rheumatoid factor (RF) and anti-citrullinated protein antibody (ACPA) seroconversion, and finally developed overt RA.

\section{Observation}

This 46-year-old woman came to our observation in 2008 because of the presence of erythematous, clearly circumscribed painful nodules on the extensor surface of the third distal interphalangeal (DIP) joint of the right hand and the third proximal interphalangeal (PIP) joint of the left hand (Figure 1) that had started to form gradually three years before. The patient did not report associated fever or other systemic symptoms. A detailed investigation of her medical history revealed no relevant information other than heavy smoking. Physical examination revealed mobile and tender cutaneous nodules, but no signs of arthritis, and her complete blood count, C-reactive protein, serum and urine urate levels, and erythrocyte sedimentation rate were within the normal range. She had undetectable serum RF, ACPA, antinuclear and anti-ds DNA antibody, and anti-extractable nuclear antigen levels. Hand X-rays did not show any RA-related abnormalities such as bone erosions, juxta-articular osteoporosis or joint space narrowing (Figure 2A). Ultrasound longitudinal and transversal views of the nodular lesions revealed well-defined hypoechogenic structures with no detectable power-Doppler signal (Figures $2 \mathrm{~B}$ and $2 \mathrm{C}$ ).

Histological examination of a biopsy specimen of the nodule on the third DIP joint of the right hand showed findings consistent with a rheumatoid nodule (Figure 3).

Given the absence of any signs of synovitis or other systemic manifestations of RA, a diagnosis of rheumatoid nodulosis was made, regular six-monthly follow-up visits were scheduled, and non-steroidal anti-inflammatory drugs (NSAIDs) were initially given to control pain as needed.

Repeated laboratory analyses showed increasing RF values (20 IU/dL in January 2011 and $31 \mathrm{IU} / \mathrm{dL}$ in May 2011) but no ACPA. No physical signs of arthritis were reported until the end of 2011, when the patient's course was further complicated by the onset of painful and swollen small joints in the hands and feet. In particular, physical examination showed symmetric arthritis of the second PIP joints and the second metacarpo-phalangeal joints of both hands, and the first metatarso-phalangeal joints of both feet. A laboratory evaluation in October 2011 showed RF (49 IU/dL) and ACPA positivity (102 IU/dL), and the patient was diagnosed as having RA (Figure 4). Oral treatment with hydroxychloroquine at a dose of $200 \mathrm{mg}$ twice daily was started

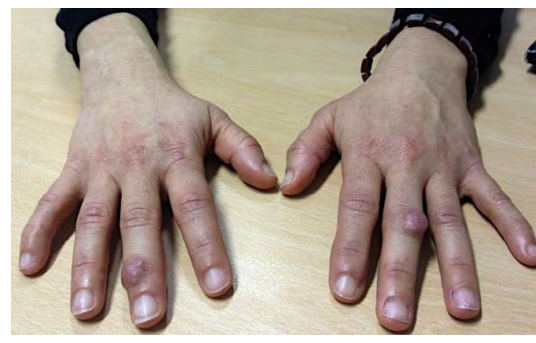

Figure 1: Skin nodules overlying the third distal interphalangeal joint of the right hand and the third proximal interphalangeal joint of the left hand.

*Corresponding author: Roberta Gualtierotti, Division of Rheumatology, Istituto Gaetano Pini, Piazza Cardinal Ferrari 1, 20122 Milano, Italy, Tel: +390258296421; Fax : +390258296315; E-mail: roberta.gualtierotti@unimi.it

Received September 21, 2013; Accepted October 21, 2013; Published October 28, 2013

Citation: Gualtierotti R, Ingegnoli F (2013) Rheumatoid Nodules Predating Seroconversion and Rheumatoid Arthritis: An Uncommon Case Report. J Clin Cell Immunol 4: 167. doi:10.4172/2155-9899.1000167

Copyright: @ 2013 Gualtierotti R, et al. This is an open-access article distributed under the terms of the Creative Commons Attribution License, which permits unrestricted use, distribution, and reproduction in any medium, provided the original author and source are credited. 


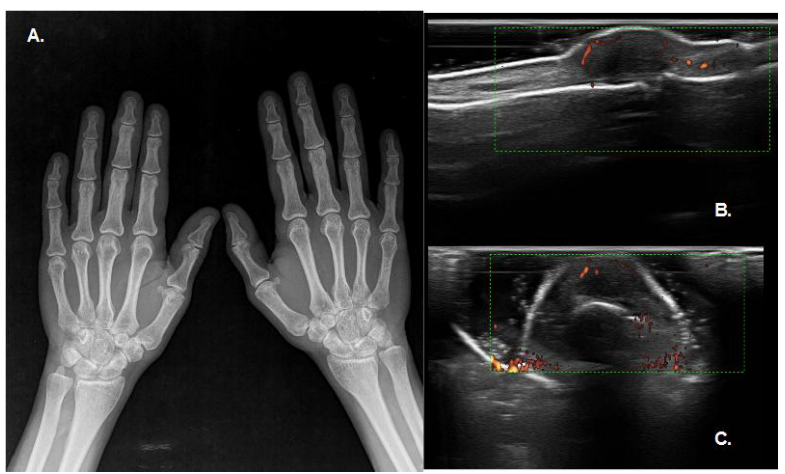

Figure 2: Plain radiograph showing no specific features of rheumatoid arthritis (A), and ultrasound imaging showing hypoechogenic nodular lesions with no Power-Doppler signal in the longitudinal and transversal views ( $B$ and $C$ ).

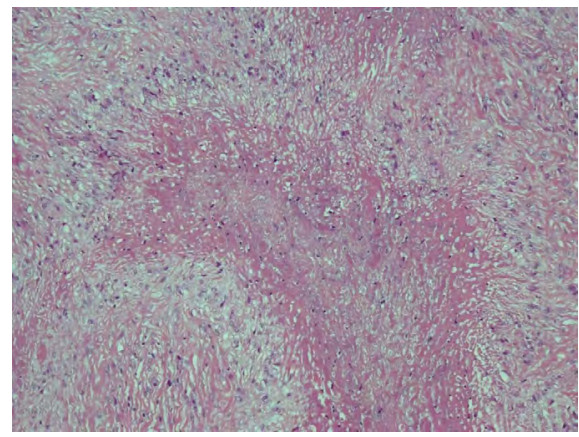

Figure 3: Histological section showing palisading histiocytes surrounding a necrotic fibrinoid center.

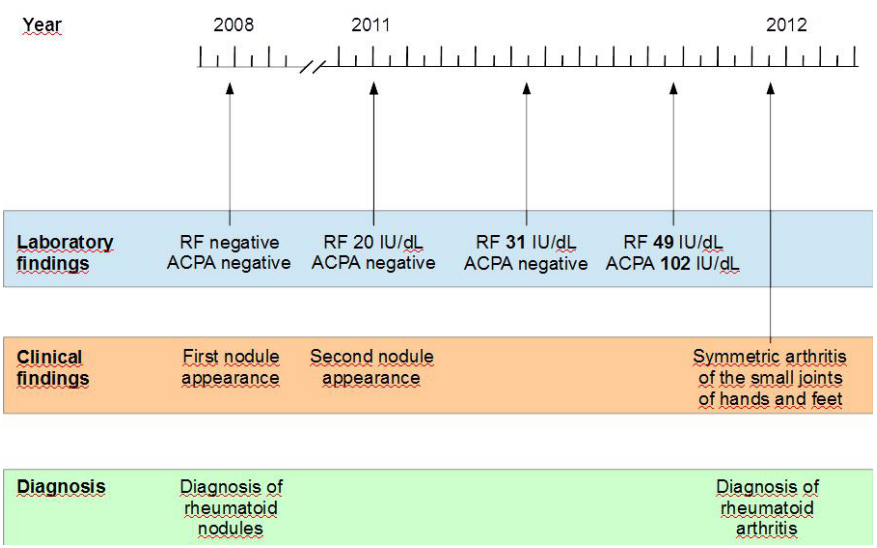

Figure 4: Summary of the patient's clinical course and the results of laboratory tests.

but, despite six months of treatment, her condition continued to deteriorate. Subsequent treatment with penicillamine $600 \mathrm{mg}$ per day improved both the joint and skin involvement.

\section{Discussion}

Rheumatoid nodules are subcutaneous lesions preferentially located on the extensor surfaces of the upper and lower extremities. A distinction must be made between classical rheumatoid nodules and benign rheumatoid nodulosis because, although they both form in areas of external pressure and have a similar histological pattern, their clinical features are different.

Classic rheumatoid nodules characteristically appear in about $25 \%$ of patients with long-standing RA, and can also be localised in extraarticular sites such as the lungs (pulmonary nodulosis) [1,2]. They are typically associated with high titres of RF and an aggressive articular and extra-articular disease outcome (i.e. joint erosions and high levels of inflammatory markers). A slightly different form of rheumatoid nodule is drug-accelerated nodulosis, which also occurs in patients with long-standing RA and may be caused or enhanced by various DMARDs [1] and anti-TNF-alpha biological therapies [3], whereas there is evidence that rituximab, an anti-CD20 biological agent, can improve it [4].

Rheumatoid nodulosis is a benign clinical entity that can occur even in the absence of RF $[5,6]$. It is usually associated with very mild or no arthritis, although cases associated with destructive polyarthritis have also been reported [7]. In the absence of articular symptoms, treatment should be aimed at pain control and reducing the size of the nodules.

The pathogenetic mechanisms underlying the development of nodules in RA are still unclear, although they may include minor traumas of small vessels that lead to immune complex aggregation and focal small vessel vasculitis, pro-inflammatory cytokines such as IL-1 [8], and a Th1-driven process [9].

The differential diagnosis of subcutaneous nodules includes rheumatoid nodules, gouty tophi, subcutaneous granuloma annulare, tumoral calcinosis, fibromas, xanthomas, subcutaneous sarcoidosis, lupus panniculitis, nodular or keloidal scleroderma, metastatic tumours, histoplasmosis, amyloidosis, ganglion cysts, foreign body granulomas, basal cell carcinomas, epidermoid cysts, and synovial cysts. Histology allows the possible causes to be differentiated.

Even in the absence of arthritis, the presence of rheumatoid nodules confirmed by a biopsy requires regular follow-up examinations and a detailed patient history concentrating on the possible signs or symptoms of RA.

As far as treatment is concerned, rheumatoid nodulosis is selflimiting and symptomatically controlled by NSAIDs. Slow-acting antiRA drugs may also be used in the case of joint swelling and tenderness, although it has been reported that methotrexate paradoxically worsens nodules while improving disease activity [10]. It has been documented that hydroxychloroquine can lead to complete resolution [11], but it provided no benefit to our patient.

Seroconversion preceding clinical manifestations has been reported not only in patients with RA [12], but also in those with systemic sclerosis [13] or systemic lupus erythematosus [14]. It has also been reported in patients with rheumatoid nodulosis [7], but our case is particular because of the uncommon succession of events: 1) the appearance of nodules in an otherwise healthy woman; 2) the subsequent appearance of slightly positive serum RF levels; and 3) the final increase in RF titre, the appearance of high-titre ACPA, and the onset of overt RA.

\section{Conclusions}

Our case is an example of a patient who developed RA during the follow-up of rheumatoid nodulosis, with an unusual evolution of rheumatoid nodules predating seroconversion and the onset of arthritis. RA could only be diagnosed on the basis of observation and follow-up. 
Citation: Gualtierotti R, Ingegnoli F (2013) Rheumatoid Nodules Predating Seroconversion and Rheumatoid Arthritis: An Uncommon Case Report. J Clin Cell Immunol 4: 167. doi:10.4172/2155-9899.1000167

Page 3 of 3

Our case suggests that more frequent clinical monitoring of patients with rheumatoid nodulosis is warranted, mainly because of its potential evolution to overt RA.

\section{Acknowledgement}

We would like to thank Dr. A. Parafioriti and Dr. A. Di Bernardo of our Department of Pathology for kindly providing the images of the histological sections.

\section{References}

1. Ziff M (1990) The rheumatoid nodule. Arthritis Rheum 33: 761-767.

2. Turesson C, O'Fallon WM, Crowson CS, Gabriel SE, Matteson EL (2003) Extra-articular disease manifestations in rheumatoid arthritis: incidence trends and risk factors over 46 years. Ann Rheum Dis 62: 722-727.

3. Toussirot E, Berthelot JM, Pertuiset E, Bouvard B, Gaudin P, et al. (2009) Pulmonary nodulosis and aseptic granulomatous lung disease occurring in patients with rheumatoid arthritis receiving tumor necrosis factor-alphablocking agent: a case series. J Rheumatol 36: 2421-2427.

4. De Stefano R, Frati E, Nargi F, Menza L (2011) Efficacy of rituximab on pulmonary nodulosis occurring or increasing in patients with rheumatoid arthritis during anti-TNF- $\alpha$ therapy. Clin Exp Rheumatol 29: 752-753.

5. Wisnieski JJ, Askari AD (1981) Rheumatoid nodulosis. A relatively benign rheumatoid variant. Arch Intern Med 141: 615-619.

6. Zeng YP, Qu T (2012) Seronegative rheumatoid nodulosis: a new case report. Eur J Dermatol 22: 425-426.
7. Maldonado I, Eid H, Rodriguez GR, Rillo OL, Barcat JA, et al. (2003) Rheumatoid nodulosis: is it a different subset of rheumatoid arthritis? J Clin Rheumatol 9: 296-305

8. Miyasaka N, Sato K, Yamamoto K, Goto M, Nishioka K (1989) Immunological and immunohistochemical analysis of rheumatoid nodules. Ann Rheum Dis 48 : 220-226.

9. Hessian PA, Highton J, Kean A, Sun CK, Chin M (2003) Cytokine profile of the rheumatoid nodule suggests that it is a Th1 granuloma. Arthritis Rheum 48: 334-338.

10. Couret M, Combe B, Chuong VT, Leroux JL, Blotman F, et al. (1988) Rheumatoid nodulosis: report of two new cases and discussion of diagnostic criteria. J Rheumatol 15: 1427-1430.

11. McCarty DJ (1991) Complete reversal of rheumatoid nodulosis. J Rheumatol 18: $736-737$.

12. Rantapää-Dahlqvist $S$ (2009) What happens before the onset of rheumatoid arthritis? Curr Opin Rheumatol 21: 272-278.

13. Englert H, Champion D, Wu JC, Giallussi J, McGrath M, et al. (2011) Antitopoisomerase antibody positivity predates nailfold capillaroscopy abnormalities in scleroderma. Postulated classification of 'prescleroderma'. Intern Med J 41: 197-199.

14. Arbuckle MR, McClain MT, Rubertone MV, Scofield RH, Dennis GJ, et al. (2003) Development of autoantibodies before the clinical onset of systemic lupus erythematosus. N Engl J Med 349: 1526-1533.
Citation: Gualtierotti R, Ingegnoli F (2013) Rheumatoid Nodules Predating Seroconversion and Rheumatoid Arthritis: An Uncommon Case Report. J Clin Cell Immunol 4: 167. doi:10.4172/2155-9899.1000167
Submit your next manuscript and get advantages of OMICS Group submissions

Unique features:

- User friendly/feasible website-translation of your paper to 50 world's leading languages

- Audio Version of published paper

- Digital articles to share and explore

Special features:

- 250 Open Access Journals

- 20,000 editorial team

21 days rapid review process

- Quality and quick editorial, review and publication processing

- Indexing at PubMed (partial), Scopus, EBSCO, Index Copernicus and Google Scholar etc

- Sharing Option: Social Networking Enabled

- Authors, Reviewers and Editors rewarded with online Scientific Credits

- Better discount for your subsequent articles

Submit your manuscript at: www.editorialmanager.com/clinicalgroup 